\title{
A Giant Keratoacanthoma Treated with Surgical Excision
}

\author{
Hyochun Park, \\ Hannara Park, \\ Hoonnam Kim, \\ Hyeonjung Yeo \\ Department of Plastic and Reconstructive \\ Surgery, Daegu Fatima Hospital, Daegu, \\ Korea
}

No potential conflict of interest relevant to this article was reported.

\begin{abstract}
A keratoacanthoma is a rapidly growing cutaneous tumor that spontaneously involutes in most instances. A giant keratoacanthoma is a rare variant and are characterized by lesions larger than $20 \mathrm{~mm}$ in diameter. We report a 56 -year-old man with a rapidly growing tumor of the right cheek, which was diagnosed as keratoacanthoma. The mass was excised completely under general anesthesia, followed by Limberg flap for reconstruction. Intraoperative frozen section histology suggested the lesion to be a well-differentiated squamous cell carcinoma, whereas final histopathology was consistent with keratoacanthoma. We herein report the first case of a giant keratoacanthoma treated with surgical excision in Korea and discuss the clinical and histopathological features of keratoacanthoma, with a review of the literature.
\end{abstract}

Keywords: Keratoacanthomas / Squamous cell carcinoma / Operative surgical procedure

\section{INTRODUCTION}

A keratoacanthoma is a rapidly growing cutaneous tumor that spontaneously involutes in most instances. The classic lesion reaches full size of 10 to $25 \mathrm{~mm}$ within 6 to 10 weeks, followed by spontaneous regression within 6 months. A giant keratoacantho$\mathrm{ma}$ is a rare variant and are characterized by lesions larger than 20 mm in diameter [1-3].

To the best of our knowledge, only 5 cases of giant keratoacanthoma have been reported in Korea, all of which were treated with intralesional injection [4-7]. We herein report the first case of a giant keratoacanthoma treated with surgical excision.

\section{CASE REPORT}

A previously healthy 56-year-old man presented with a rapidly

Correspondence: Hyochun Park

Department of Plastic and Reconstructive Surgery, Daegu Fatima Hospital,

99 Ayang-ro, Dong-gu, Daegu 41199, Korea

E-mail:phc3900@hanmail.net

Received February 14, 2015 / Revised June 1, 2015 / Accepted August 4, 2015 growing exophytic tumor on the right cheek. The patient first noticed the lesion four weeks prior. There was no history of trauma or no significant past medical history. Physical examination revealed a well-demarcated, dome-shaped, $2.7 \times 2.7 \mathrm{~cm}$ cutaneous tumor with a central crater (Fig. 1). There was no evidence of regional lymphadenopathy. The remainder of physical examination and all preoperative laboratory tests were unremarkable.

Two weeks later, the mass was excised completely under general anesthesia (Fig. 2A, C). Intraoperative frozen biopsy of the margin was suggestive of well-differentiated squamous cell carcinoma (SCC). Because of this, an additional margin of $4 \mathrm{~mm}$ was resected. The resulting defect was resurfaced with a Limberg flap (Fig. $2 \mathrm{~B}, \mathrm{D})$. The wound healed without any significant vascular issues in the flap. However, unlike intraoperative frozen section histology, final histopathology was consistent with keratoacanthoma (Fig. 3). The patient was discharged home at 5 days. During the follow-up period, the patient showed satisfactory progress from both aesthetic and functional perspectives. 


\section{DISCUSSION}

Keratoacanthomas are common but unique tumors with a rapid growth rate. Clinically, keratoacanthomas tend to be solitary tumors appearing mainly on sun-exposed areas in persons of light complexion, with the majority appearing on the face, forearms, or hands. Peak incidence is usually in the fifth decade of life. In gen-

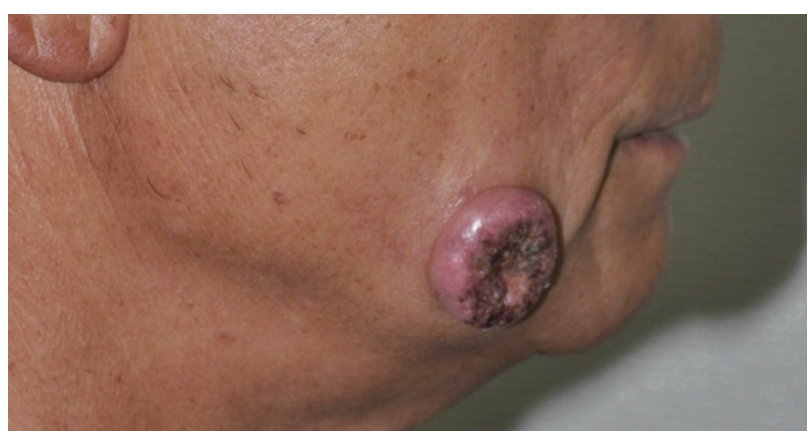

Fig. 1. Clinical presentation. This otherwise healthy 56-year-old patient presented with the mass, which had grown over just four weeks prior to this photograph was taken.
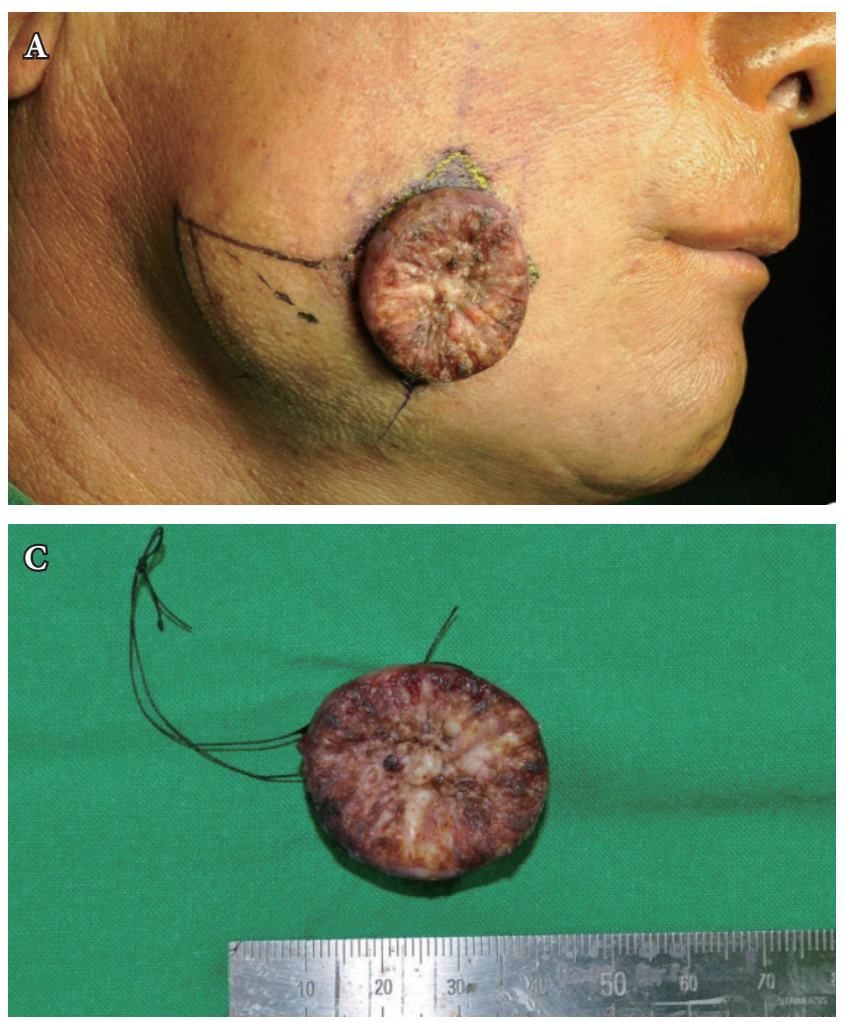

eral, there are three distinct stages in the natural history of a keratoacanthoma: proliferative, mature, and resolving. The classic lesion shows rapid progression and usually reaches full size within 6 to 10 weeks during the proliferating period. This is followed by an involution phase, which may occur after a few months and eventually results in a slightly depressed and often hypopigmented scar $[1,2,8]$. The entire cycle from proliferation to spontaneous involution usually takes about 4 to 6 months. However, certain lesions may last a year or more [2].

Multiple treatment modalities have been employed for keratoacanthoma: surgical excision, Mohs' micrographic surgery, curettage and electrodesiccation, cryosurgery, argon laser, radiotherapy, topical medication, and intralesional injection [1,2].

Clinically, keratoacanthomas can be recognized by the distinctive appearance of the rapidly growing, raised, non-pigmented lesion with a central keratin plug. This presentation shares similarity with rapidly growing atypical SCC, with the most significant difference in spontaneous resolution of keratoacanthoma [9]. Both
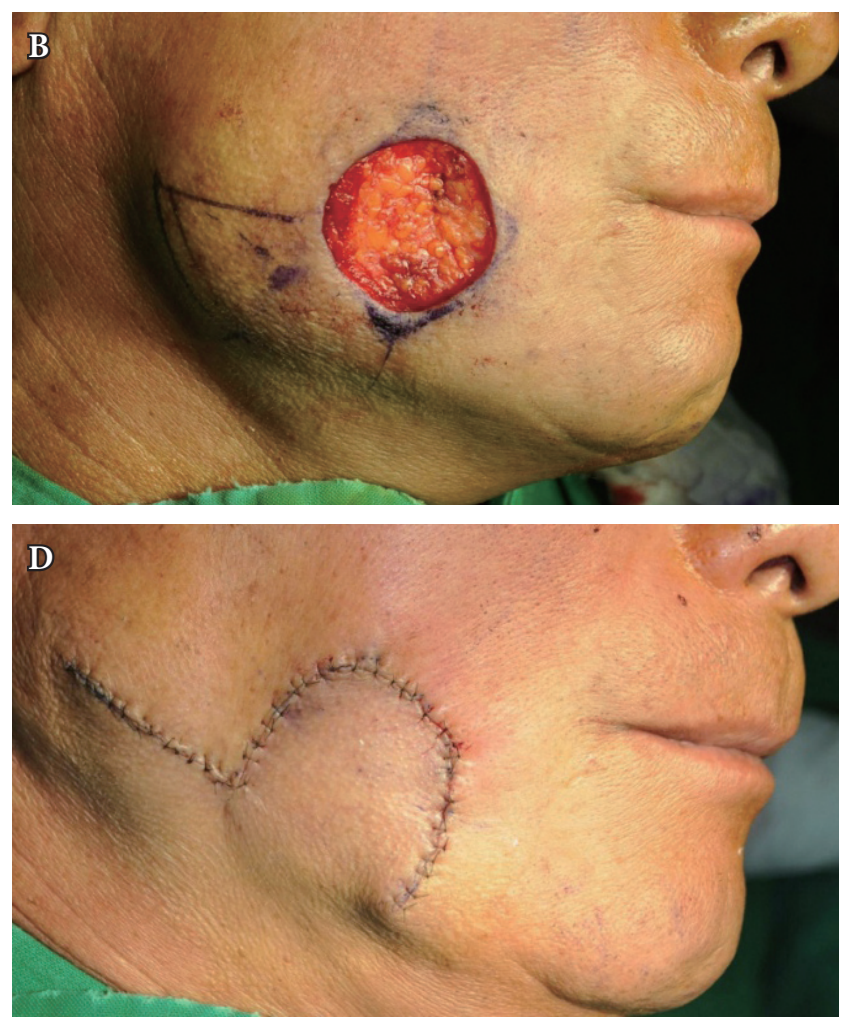

Fig. 2. (A) Preoperative planning included excision and Limberg flap reconstruction. (B) The mass was excised, leaving a 3.0 diameter soft tissue defect. (C) Intraoperative frozen section of the wound margin was suggestive of squamous cell carcinoma, and an additional 4-mm margin was further resected. (D) The resulting defect was closed with the flap. 
keratoacanthoma and invasive SCC are common keratinocytic neoplasms. However, keratoacanthomas rarely spread via lymphatic, venous, or perineural routes [10-12]. It is important to note that keratoacanthoma has been found in close proximity to SCC, which suggests that a keratoacanthoma cannot be reliably distin-
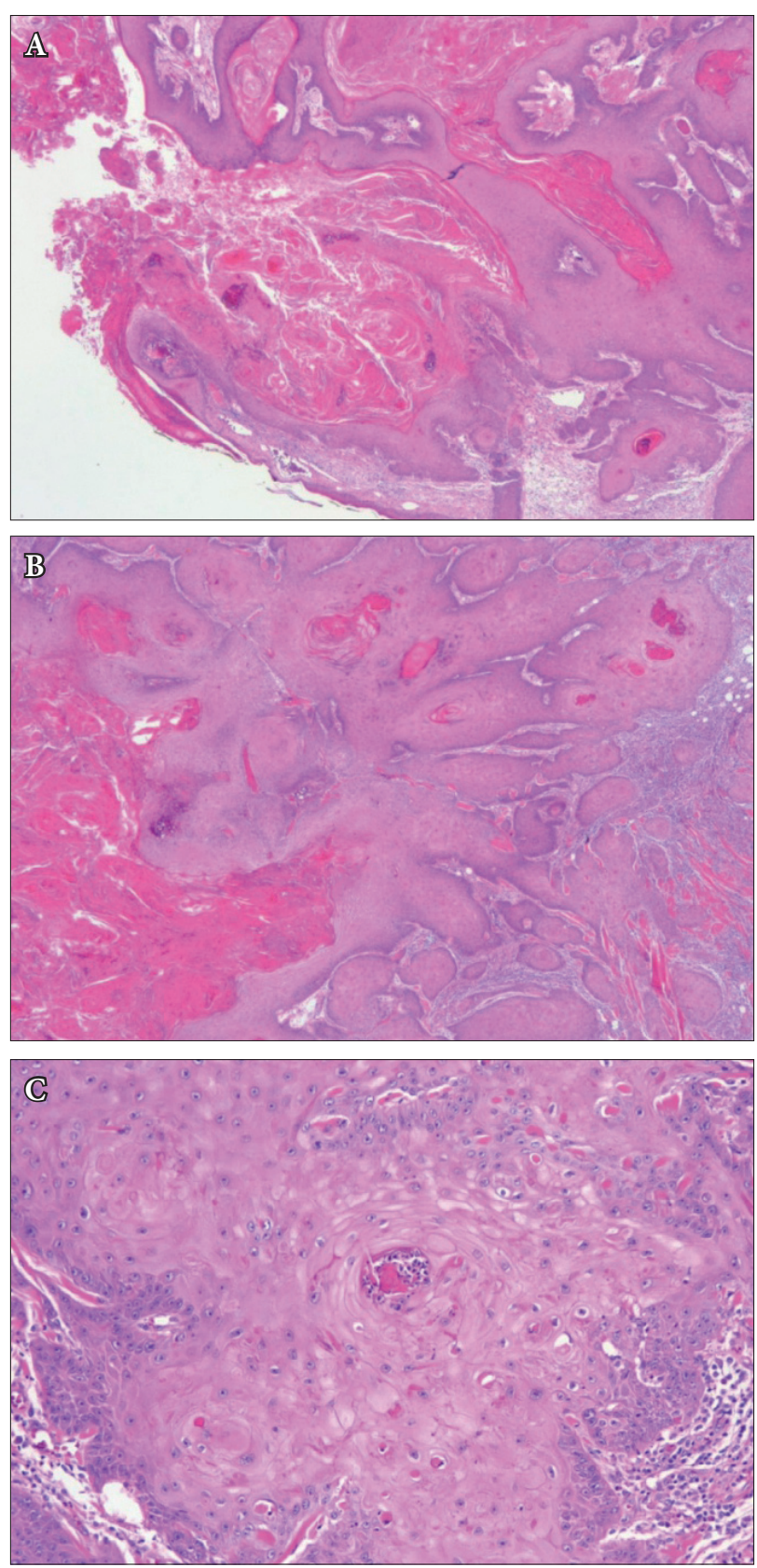

Fig. 3. (A, B) Solid proliferations of squamous epithelium. Formations of a central crater filled with parakeratotic keratin $(\mathrm{H} \& \mathrm{E}, \times 20)$. (C) Squamous proliferation where cells show mild atypia and the dermis was infiltrated with multiple polymorphonuclear cells $(\mathrm{H} \& \mathrm{E}, \times 100)$. guished from SCC on histopathologic examination $[9,13]$.

Management of keratoacanthoma leaves surgeons with a clinical dilemma. Some keratoacanthomas may show spontaneous regression within several months, which has prompted some surgeons to advocate an observational stance [2]. Furthermore, surgical excision of a giant keratoacanthoma in complicated anatomic locations may require extensive surgical reconstruction with significant morbidity [14]. Despite these factors, giant keratoacanthomas often do not spontenaeously resolve and tend not to respond to intralesional injections with cytotoxic agents. As such, surgical excisions are usually reserved for the larger lesion [15].

A major challenge in management of these tumors is the difficulty in histologic and clinical differential diagnosis with regard to SCC [1]. Macroscopic and histological examinations are very important for establishment of the proper diagnosis and management, especially for larger tumors similar to the case presented. Awareness of the possible malignant transformation of a keratoacanthoma is important, and the patient's history, clinical finding, and histopathology must be correlated to avoid further complications.

\section{REFERENCES}

1. Garcia-Zuazaga J, Ke M, Lee P. Giant keratoacanthoma of the upper extremity treated with mohs micrographic surgery: a case report and review of current treatment modalities. J Clin Aesthet Dermatol 2009;2:22-5.

2. de Visscher JG, van der Wal KG, Blanken R, Willemse F. Treatment of giant keratoacanthoma of the skin of the lower lip with intralesional methotrexate: a case report. J Oral Maxillofac Surg 2002;60:93-5.

3. Rani N, Kumar P, Patil JD, Choudhary SS. Keratoacanthoma centrifugam marginatum: an atypical presentation. J Postgrad Med 2013;59: 58-60.

4. Kim CW, Kim CH, Lim YH, Nam ES. A case of keratoacanthomalike squamous cell carcinoma of the auricle. Korean J OtolaryngolHead Neck Surg 2006;49:225-7.

5. Rho WS, Kim HB. Keratoacanthoma of the eye lid. J Korean Ophthalmol Soc 1986;27:1085-9.

6. Shin SJ, Park DH. Clinical experience of cutaneous squamous cell carcinoma arising in keratoacanthoma. J Korean Soc Plast Reconstr Surg 2006;33:506-9.

7. Hong HS, Ahn H, Eom JW. A case of giant keratoacanthoma of the lower lip treated with intralesional methotrexate. Korean J Otolaryngol-Head Neck Surg 1997;40:1858-62.

8. Schwartz RA. Keratoacanthoma: a clinico-pathologic enigma. Der- 
matol Surg 2004;30:326-33.

9. Hopkins K, Paul S, Weedon D, Rosendahl C. Use of double-bladed biopsy in distinguishing keratoacanthoma from squamous cell carcinoma: a case report. Dermatol Pract Concept 2013;3:43-6.

10. Pyne JH, Windrum G, Sapkota D, Wong JC. Keratoacanthoma versus invasive squamous cell carcinoma: a comparison of dermatoscopic vascular features in 510 cases. Dermatol Pract Concept 2014;4:37-41.

11. Godbolt AM, Sullivan JJ, Weedon D. Keratoacanthoma with perineural invasion: a report of 40 cases. Australas J Dermatol 2001;42:168-71.

12. Tschandl P, Rosendahl C, Williamson R, Weedon D. A keratoacan- thoma with venous invasion. Dermatol Pract Concept 2012;2:204a03.

13. Ko CJ. Keratoacanthoma: facts and controversies. Clin Dermatol 2010;28:254-61.

14. Spieth K, Gille J, Kaufmann R. Intralesional methotrexate as effective treatment in solitary giant keratoacanthoma of the lower lip. Dermatology 2000;200:317-9.

15. Parvanescu H, Mogoanta L, Foarfa C, Ciurea M, Georgescu A, Nicolae C. Giant keratoacanthoma of the hand. Rom J Morphol Embryol 2005;46:235-8 